\title{
Influence of Mo on the Fe:Mo:C nano-catalyst thermodynamics for single-walled carbon nanotube growth
}

\author{
Stefano Curtarolo ${ }^{1, *}$, Neha Awasthi ${ }^{1}$, Wahyu Setyawan ${ }^{1}$, Aiqin Jiang ${ }^{1}$, \\ Kim Bolton ${ }^{2}$, Toshio Tokune ${ }^{3}$, Avetik R. Harutyunyan ${ }^{3}$ \\ ${ }^{1}$ Department of Mechanical Engineering and Materials Science Duke University Durham, NC 27708 \\ ${ }^{2}$ University College of Boraas SE-501 90 Boraas and Physics Department Göteborg University SE-412 96 Göteborg, Sweden \\ ${ }^{3}$ Honda Research Institute USA Inc. 1381 Kinnear Road Columbus, OH 43212 \\ *corresponding author: stefano@duke.edu
}

(Dated: October 25, 2018)

\begin{abstract}
We explore the role of Mo in Fe:Mo nanocatalyst thermodynamics for low-temperature chemical vapor deposition growth of single walled carbon nanotubes (SWCNTs). By using the size-pressure approximation and $a b$ initio modeling, we prove that for both Fe-rich ( $\sim 80 \% \mathrm{Fe}$ or more) and Mo-rich ( 50\% Mo or more) Fe:Mo clusters, the presence of carbon in the cluster causes nucleation of $\mathrm{Mo}_{2} \mathrm{C}$. This enhances the activity of the particle since it releases Fe, which is initially bound in a stable Fe:Mo phase, so that it can catalyze SWCNT growth. Furthermore, the presence of small concentrations of Mo reduce the lower size limit of low-temperature steady-state growth from $\sim 0.58 \mathrm{~nm}$ forpureFeparticlesto $\sim 0.52 \mathrm{~nm}$. Our ab initio-thermodynamic modeling explains experimental results and establishes a new direction to search for better catalysts.
\end{abstract}

Critical factors for the efficient growth of single walled carbon nanotubes (SWCNTs) via catalytic chemical vapor deposition (CCVD) $)^{1,2,3}$ are the compositions of the interacting species (feedstock, catalyst, support $4,5,6,7,8,9,10$ ), the preparation of the catalysts, and the synthesis conditions $11,12,13,14,15,16,17,18$. Efficient catalysts must have long active lifetimes (with respect to feedstock dissociation and nanotube growth), high selectivity and be less prone to contamination $19,20,21,22,23$. Common factors that lead to reduction in catalytic activity are deactivation (i.e. chemical poisoning or coating with carbon), thermal sintering (e.g. caused by highly exothermic reactions on the clusters surface $13,14.24$ with insufficient heat transfer ${ }^{25,26}$ ) and solid-state reactions (nucleation of inactive phases in the cluster $22,23,25$ ).

Metal alloy catalysts, such as Fe:Co, Co:Mo and Fe:Mo, improve the growth of CNTs $4,10,20,27,28,29,30,31$, because the presence of more than one metal species can significantly enhance the activity of a catalyst $20,32,33,34$, and can prevent catalyst particle aggregation $20,31,32,33$. In the case of Fe:Mo nanoparticles supported on $\mathrm{Al}_{2} \mathrm{O}_{3}$ substrates, the enhanced catalyst activity has been shown to be larger than the linear combination of the individual $\mathrm{Fe} / \mathrm{Al}_{2} \mathrm{O}_{3}$ and $\mathrm{Mo} / \mathrm{Al}_{2} \mathrm{O}_{3}$ activities $20,27,28$. This is explained in terms of substantial inter-metallic interaction between Mo, Fe and $\mathrm{C} 20,35,36$ which is congruent with previously observed solid-state reactions between these elements. In fact, the addition of Mo in mechanical alloying of powder $\mathrm{Fe}$ and $\mathrm{C}$ mixtures ${ }^{38}$ promotes solid state reactions even at low Mo concentrations by forming ternary phases, such as the $(\mathrm{Fe}, \mathrm{Mo}){ }_{23} \mathrm{C}_{6}$ type carbides ${ }^{38}$.

The way in which carbon interacts with transition metals depends on the metal species. Fe and Co belong to the "carbon dissolution-precipitation mechanism" group, where relatively large fractions of carbon dissolve into the cluster before stable carbides are formed, while Mo belongs to the "carbide formation-decomposition" group where carbide formation occurs rapidly at low carbon concentrations ${ }^{39}$. These mechanisms are governed by the interplay between solubility of $\mathrm{C}$ in the metal matrix (interstitial and/or substitutional defects) and the ease of metal carbide formation. Although relating $\mathrm{C}$ solubility and catalytic ability of metal catalysts is not simple (factors like temperature, diffusion, kinetics and particle size have to be considered ${ }^{22,23}$ ), metals which form carbides can be efficient catalysts as long as they offer sufficient carbon solubility, even if the formation of the carbides interferes with the SWCNT growth, as is the case of $\mathrm{Fe}^{22}, 23$. Co can dissolve a relatively large fraction of carbon $\mathrm{C}$ and does not form stable ordered carbides, whereas Mo has limited C solubility and forms several stable carbides (even at low temperature). Similarly to $\mathrm{Co}, \mathrm{Fe}$ can dissolve a relatively large fraction of $\mathrm{C}$ (at least in the $\gamma$ phase), but concomitantly it forms carbides at temperatures relevant to SWCNT growth $\left(\mathrm{Fe}_{3} \mathrm{C}\right)^{35}, 36$. Nucleation of $\mathrm{Fe}_{3} \mathrm{C}$ and subsequent loss of $\mathrm{C}$ solubility 20 can be used to identify the thermodynamic lower limit for the CVD growth of very thin SWCNTs from $\mathrm{Fe}$ nanoparticles ${ }^{22,23}$. Thus, for efficient CVD growth from $\mathrm{Fe}, \mathrm{Mo}, \mathrm{Fe}: \mathrm{Mo}$ and Co:Mo clusters, the particles must be small (dispersed) and metallic (preserved from carbidization). In fact, active catalyst species in Co:Mo catalysis are also small metallic species 32,33 with Mo added to limit particle aggregation by forming molybdate species which are later reduced to give small metallic Co:Mo nanoparticles. It has been shown that disruption of the Co-Mo interactions leads to a lower SWCNT growth efficiency $\underline{40}$.

The use of alloys instead of pure metals provides additional degrees of freedom, such as fractions of the metal species, which has chemical and thermodynamic advan- 
tages. The chemical advantages arise since the fractions of constituent species can be tailored to enhance catalytic performance that can be measured by the yield and quality of nanotubes $32,33,34$. It has been found that low Fe:Mo ratios are favorable for growing SWCNTs (on $\mathrm{Al}_{2} \mathrm{O}_{3}$ substrates) since the presence, after activation, of the phase $\mathrm{Fe}_{2}\left(\mathrm{MoO}_{4}\right)_{3}$ can lead to the formation of small metallic clusters 34 (the best compromise between catalytic activity and SWCNT selectivity was found to be $\mathrm{Fe}_{3.5} \mathrm{Mo}_{11.5}$, Ref $\left.{ }^{34}\right)$. High fractions of Fe in Fe:Mo lead to formation of larger particles during the reduction step which are inactive for SWCNT growth, unless precautions are taken to avoid excessive sintering 20 (no formation of molybdate species has been reported when using $\mathrm{CH}_{4}$ feedstock with Fe:Mo catalysts 20 and hence the chemical role of Mo in Fe:Mo is different from that in Co:Mo). The thermodynamic advantages are revealed when considering the vapor-liquid-solid model (VLS), which is the most probable mechanism for CNT growth ${ }^{12,20,41}$. The metallic nanoparticles are very efficient catalysts when they are in the liquid or viscous states $\underline{20}$, probably because one has considerable carbon bulk-diffusion in this phase (compared to surface or sub-surface diffusion). Generally, unless stable intermetallic compounds form, alloying metals reduce the melting point below those of the constituents 35,36 . This happens, for instance, with the addition of small fractions of Mo to Fe. Hence, to enhance the yield and quality of nanotubes, one can tailor the composition of the catalyst particle to move its liquidus line below the synthesis temperature $\mathrm{e}^{20}$. However, identifying the perfect alloy composition is non trivial. In fact, the presence of more than two metallic species allows for the possibility of different carbon pollution mechanisms by allowing thermodynamic promotion of ternary carbides. So far, due to the very complex interplay between competing phases at the nano-scale (even for pure Fe particles 22,23 ), the search for the proper catalyst composition has been empirical20,32,33,34,40.

In the present manuscript we address the interaction between $\mathrm{C}$ and Mo:Fe nanoparticles. We use thermodynamic and quantum mechanical results to discuss the complexity of Fe- ( $\sim 80 \%$ Fe or more) and Mo-rich ( $\sim 50 \%$ Mo or more) Fe:Mo catalysts, previously addressed phenomenologically. The results are useful for the development of efficient catalysts for nanotube and graphene growth.

Methods. Investigating the behavior of $\mathrm{C}$ in Fe:Mo nanoparticles requires an understanding of the interplay of the various phases of the $\mathrm{Fe}-\mathrm{Mo}-\mathrm{C}$ system at the nanoscale. Determining the thermodynamic stability of different phases in nanoparticles of different sizes with $a b i n i-$ tio calculations is complicated and computationally expensive. In Ref ${ }^{22,23}$ we have developed a simple model, called the "size-pressure approximation", which allows one to estimate the phase diagram at the nanoscale starting from bulk calculations under pressure.
The size-pressure approximation. Surface curvature and superficial dangling bonds on nanoparticles are responsible for internal stress fields which modify the atomic bond lengths. For spherical clusters, the phenomenon can be modeled with the Young-Laplace equation $\Delta P=2 \gamma / R$ where the parameter $\gamma$ (surface tension for liquid particles) can be calculated with ab initio methods. As a first approximation, where all surface effects that are not included in the curvature are neglected, the study of phase diagrams for spherical particles can be mapped onto the study of phase diagrams for bulk systems under the same pressure that is produced by the curvature. It is important to mention that $\gamma$ is not a real surface tension but an ab initio fitting parameter describing size-induced stress in nanoparticles. In our case, it can be assumed that $\gamma$ is independent of the fraction of Mo (since the best Fe:Mo catalysts are Fe-rich) and $\mathrm{C}$ (since the amount of $\mathrm{C}$ in the catalytically active par-

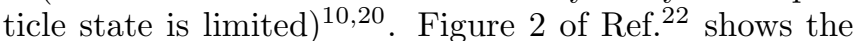
implementation of the "size-pressure approximation" for Fe nanoparticles. The idea is simple. Two interpolations are involved: "pressure versus distortion" and "distortion versus curvature" are coupled to obtain a relation "pressure versus curvature" (where curvature is $1 / R^{22}$ ). In more details, the left hand side of Figure 2 of Ref. ${ }^{22}$ shows the average distortion of the bond length inside the cluster $\Delta d_{n n} \equiv d_{n n}^{0}-d_{n n}$ for a variety of spherical bcc particles as a function of the inverse radius $(1 / R)$. The right hand side shows the compression of the bond length as a function of the hydrostatic pressure for the bulk system. Combining the two sets of data yields:

$$
P \cdot R=2.46 \mathrm{GPa} \cdot \mathrm{nm} \quad\left(\gamma=1.23 \mathrm{~J} / \mathrm{m}^{2}\right) .
$$

Equation (11) is used to deduce the Fe-Mo-C phase diagram of nanoparticles of radius $R$ from ab initio calculations of the bulk material under pressure $P$. The parameter $\gamma$ compares well with the experimental values of the surface tension of bulk Fe at the melting point $~$ $1.85 \mathrm{~J} / \mathrm{m}^{242}$ and $\sim 1.90^{\underline{43}}$. For a detailed explanation of the "size-pressure approximation" see Ref ${ }^{22}$.

The assumption of $\gamma$ being independent of the Mo concentration is justified at zero (and low) temperature because molybdenum tends to segregate inside the particle, so that it can not affect the chemistry and the bonding states at the surface (see the section "surface energies" near the end of the manuscript). At high temperature, Mo would eventually populate the surface and modify $\gamma$. To a first approximation, by linearly interpolating between the experimental values of the surface tension for $\mathrm{Fe}\left(1.85 \mathrm{~J} / \mathrm{m}^{2}\right)$ and $\mathrm{Mo}\left(2.08 \mathrm{~J} / \mathrm{m}^{2}\right)$ (i.e. Vegard's law), and assuming that the parameter $\gamma$ follows the same trend, we would obtain a $\sim 3 \%$ increase for $\gamma$ at the optimal composition $\mathrm{Fe}_{4} \mathrm{Mo}$ of the catalyst (see below). Thus, all the estimated radii and diameters deduced from equation 1 might be overestimated of few percent at high temperature (energies and pressures are not affected by 
$\gamma$ ). Considering the formidable computational needs required to obtain a concentration-dependent parameterization of $\gamma$, we believe that our calculated value is accurate enough to describe the general trends of size-induced thermodynamics and activity.

Quantum mechanical calculations. Simulations are performed with VASP $\underline{44}$, using projector augmented waves (PAW) $\underline{45}$ and exchange-correlation functionals as parameterized by Perdew, Burke and Ernzerhof (PBE) ${ }^{46}$ for the generalized gradient approximation (GGA). Simulations are carried out with spin polarization, at zero temperature, and without zero-point motion. All structures are fully relaxed. Numerical convergence to within about $2 \mathrm{meV} /$ atom is ensured by enforcing a high energy cut-off $(500 \mathrm{eV})$ and dense k-meshes. The hydrostatic pressure estimated from the pressure-size model is implemented as Pulay stress 47 . Ternary phase diagrams are calculated using bcc-Mo, bcc-Fe and SWCNTs as references (pure-Fe phase is taken to be bcc because our simulations are aimed at the low temperature regime of catalytic growth). The reference SWCNTs have the same diameter of the particle to minimize the curvature-strain energy. In fact, CVD experiments of SWCNT growth from small $(\sim 0.6-2.1 \mathrm{~nm})$ particles indicate that the diameter of the nanotube is similar to the diameter of the catalyst particle from which it grows. In some experiments where the growth mechanism is thought to be root-growth, the ratio of the catalyst particle diameter to SWCNT diameter is $\sim 1.0$, whereas in experiments involving pre-made floating catalyst particles this ratio is $\sim 1.6^{48}$. Formation energies are calculated with respect to decomposition into the nearby stable elements or phases, depending the position in the ternary phase diagram as described later.

Competing phases. Pure elements (bcc-Fe, bcc-Mo and SWCNT-C) are included in the calculation in their most stable low temperature configurations. Other phases are included if they are stable in the temperature range used in CVD growth of SWCNTs or if they have been reported experimentally during or after the growth $35,36,37$. Thus, we include the binaries $\mathrm{Mo}_{2} \mathrm{C}, \mathrm{Fe}_{2} \mathrm{Mo}$ and $\mathrm{Fe}_{3} \mathrm{C}^{35,36}$. In addition, since our Fe-rich Mo:Fe experiments were performed with compositions close to $\mathrm{Fe}_{4} \mathrm{Mo}^{20}$, we include a random phase $\mathrm{Fe}_{4} \mathrm{Mo}$ generated with the special quasi-random structure formalism (SQS). Bulk ternary carbides, which have been widely investigated due to their importance in alloys and steel, can be considered as derivatives of binary structures with extra $\mathrm{C}$ atoms in the interstices of the basic metal alloy structures. Three possible ternary phases have been reported for bulk Fe-Mo-C ${ }^{49}$ and they are referred as $\tau_{1}\left(M_{6} \mathrm{C}\right), \tau_{2}$ $\left(M_{3} \mathrm{C}\right)$ and $\tau_{3}\left(M_{23} \mathrm{C}_{6}\right)$ ( $M$ is the metal species). For simplicity, we follow the same nomenclature. $\tau_{1}$ is the well-known $M_{6} \mathrm{C}$ phase, which has been observed experimentally as $\mathrm{Fe}_{4} \mathrm{Mo}_{2} \mathrm{C}$ and $\mathrm{Fe}_{3} \mathrm{Mo}_{3} \mathrm{C}$ structures $(\eta$

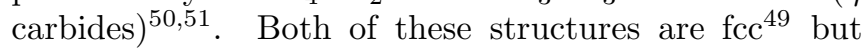

have different lattice spacings 52 . Our calculations show that the most stable variant $\tau_{1}$ is $\mathrm{Fe}_{4} \mathrm{Mo}_{2} \mathrm{C}$, and we denote it as $\tau_{1}$ henceforth. $\tau_{2}$ is the $\mathrm{Fe}_{2} \mathrm{MoC}$ phase, which has an orthorhombic symmetry distinct from that of $\mathrm{Fe}_{3} \mathrm{C}^{53,54}$. We consider $\mathrm{Fe}_{21} \mathrm{Mo}_{2} \mathrm{C}_{6}{ }^{55}$ as the third $\tau_{3}$ fcc phase. We use the $\mathrm{Cr}_{23} \mathrm{C}_{6}$ as the prototype structure ${ }^{52}$ where $\mathrm{Fe}$ and Mo substitute for Cr. Although $M_{23} \mathrm{C}_{6}$ type phases do not appear in the stable $\mathrm{C}-\mathrm{Fe}$ or CMo systems, they have been reported in ternary C-FeMo systems and also appear as transitional products in solid state reactions $\underline{49}$. Time-temperature precipitation diagrams of low- $\mathrm{C}$ steels have identified $\tau_{2}-M_{3} \mathrm{C}$, $\tau_{3}-M_{23} \mathrm{C}_{6}$ and $\tau_{1}-M_{6} \mathrm{C}$ as low-temperature, metastable and stable carbides, respectively $\stackrel{56}{ }$. Furthermore, $\tau_{2}$ $M_{3} \mathrm{C}$ carbides precipitate quickly due to carbon-diffusion controlled reaction while $\tau_{3}-M_{23} \mathrm{C}_{6}$ carbides precipitate due to substitutional-diffusion controlled reactions. The latter phenomenon, requiring high temperature, longer times and producing metastable phases ${ }^{56}$ is not expected to enhance the catalytic deactivation of the nanoparticle. In summary, as long as the presence of carbon does not lead to excessive formation of $M_{3} \mathrm{C}\left(\mathrm{Fe}_{3} \mathrm{C}\right.$ and $\tau_{2}$ $\mathrm{Fe}_{2} \mathrm{MoC}$ ), the catalyst should remain catalytically active for SWCNT growth.

Results. A structure at a given composition is considered stable (at zero temperature and without zero-point motion) if it has the lowest formation energy of all structures at this composition and, if on the ternary phase diagram, it lies below the convex hull of tie planes connecting all the other stable structures 57,58,59,60. Phases lying above the convex hull and with small positive formation energies may be favored at higher temperatures due to configurational and vibrational entropy contributions.

We generate the convex hulls with the qconvex package ${ }^{61}$. By projecting the $3 \mathrm{D}$ facets onto the $2 \mathrm{D}$ plane we obtain the graphs shown in Figure 1, where the panels (a),(b),(c) and (d) represent the phase diagrams at zero temperature of nanoparticles of radii $R \sim \infty, 1.23,0.62,0.41 \mathrm{~nm}$, calculated at $P=0,2,4$, and $6 \mathrm{GPa}$, respectively. Stable and unstable phases are shown as black squares and red dots, respectively. The solid green lines, connecting the stable phases are the projected edges of the 3D convex hull "facets". The numbers $1 \ldots 8$ in panels (c) and (d) indicate the boundary phases' crossings of our test cases, and are discussed below. Table \ shows the formation energies of the various competing phases calculated with respect decomposition into the appropriate stable components (reported in the "refs." lines).

In each panel of Figure 10 the two dotted lines connecting $\mathrm{Fe}_{4} \mathrm{Mo}$ and FeMo to SWCNT denote the introduction of carbon into the system. $\mathrm{Fe}_{4} \mathrm{Mo}$ has been reported to be an effective catalyst composition ${ }^{20}$ while FeMo represents a hypothetical Fe:Mo particle with a Mo content larger than 33\%. This Mo-rich nanoparti- 


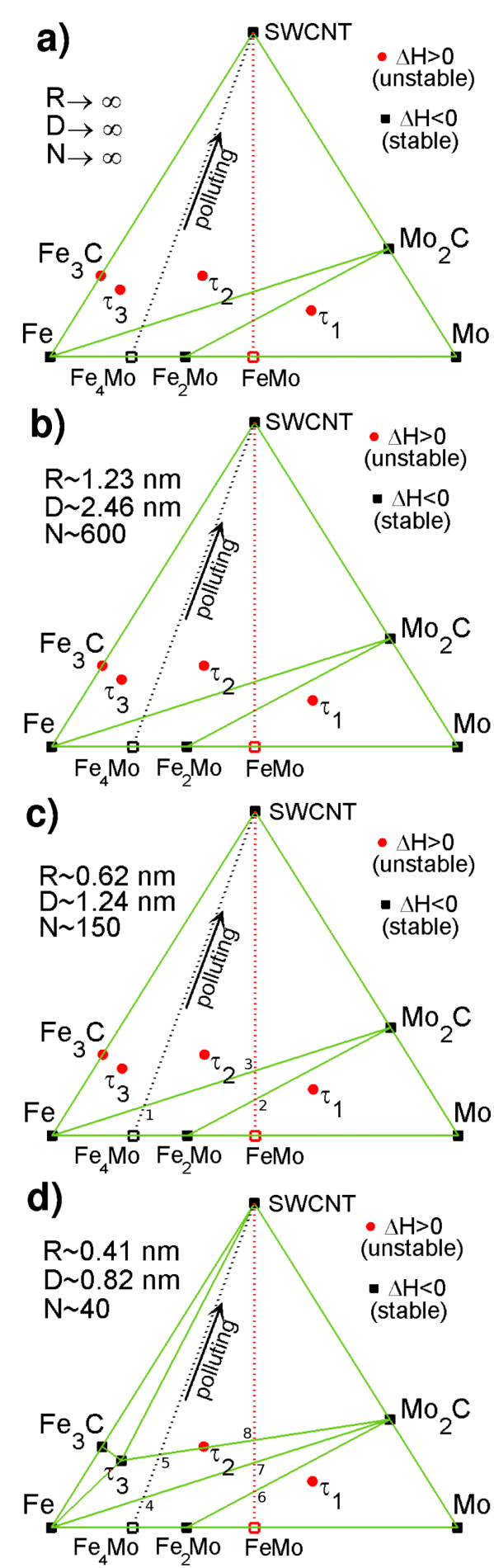

FIG. 1: (color online). Ternary phase diagram for Fe-Mo-C nanoparticles of $R \sim \infty, 1.23,0.62,0.41 \mathrm{~nm}$. Notations are explained in the text.

cle gives low yields of SWCNTs at high temperature $\underline{62}$. In thermodynamic terms, the growth of SWCNTs has to be considered as nucleation of ordered $\mathrm{C}$, hence the balance between all the competing phases along the dotted lines controls the activity of the particle. The size

\begin{tabular}{|c|c|c|c|c|}
\hline $\mathrm{R}(\mathrm{nm})$ & $\infty$ & 1.23 & 0.62 & 0.41 \\
\hline $\mathrm{P}(\mathrm{GPa})$ & 0 & 2 & 4 & 6 \\
\hline $\mathrm{N}(\#)$ & $\infty$ & $\sim 600$ & $\sim 150$ & $\sim 40$ \\
\hline Phases & (meV/at.) & (meV/at.) & (meV/at.) & (meV/at.) \\
\hline $\mathrm{Fe}_{3} \mathrm{C}$ & 48.7 & 28.9 & 6.0 & -20.9 \\
\hline (refs.) & $\mathrm{Fe}, \mathrm{C}$ & $\mathrm{Fe}, \mathrm{C}$ & $\mathrm{Fe}, \mathrm{C}$ & $\mathrm{Fe}, \mathrm{C}$ \\
\hline $\mathrm{Mo}_{2} \mathrm{C}$ & -113.7 & -131.3 & -154.3 & -185.9 \\
\hline (refs.) & $\mathrm{Mo}, \mathrm{C}$ & $\mathrm{Mo}, \mathrm{C}$ & $\mathrm{Mo}, \mathrm{C}$ & $\mathrm{Mo}, \mathrm{C}$ \\
\hline $\mathrm{Fe}_{2} \mathrm{Mo}$ & -2.0 & -6.9 & -14.1 & -21.2 \\
\hline (refs.) & $\mathrm{Fe}, \mathrm{Mo}$ & $\mathrm{Fe}, \mathrm{Mo}$ & $\mathrm{Fe}, \mathrm{Mo}$ & $\mathrm{Fe}, \mathrm{Mo}$ \\
\hline$\tau_{1}$ & 46.8 & 47.2 & 47.2 & 47.2 \\
\hline (refs.) & $\mathrm{Fe}_{2} \mathrm{Mo}$, & $\mathrm{Fe}_{2} \mathrm{Mo}$, & $\mathrm{Fe}_{2} \mathrm{Mo}$, & $\mathrm{Fe}_{2} \mathrm{Mo}$, \\
\hline (refs.) & $\mathrm{Mo}_{2} \mathrm{C}, \mathrm{Mo}$ & $\mathrm{Mo}_{2} \mathrm{C}, \mathrm{Mo}$ & $\mathrm{Mo}_{2} \mathrm{C}, \mathrm{Mo}$ & $\mathrm{Mo}_{2} \mathrm{C}, \mathrm{Mo}$ \\
\hline$\overline{\tau_{2}}$ & 451.7 & 433.4 & 413.2 & 414.6 \\
\hline (refs.) & $\mathrm{Fe}, \mathrm{C}$, & $\mathrm{Fe}, \mathrm{C}$, & $\mathrm{Fe}, \mathrm{C}$, & $\tau_{3}, \mathrm{C}$ \\
\hline (refs.) & $\mathrm{Mo}_{2} \mathrm{C}$ & $\mathrm{Mo}_{2} \mathrm{C}$ & $\mathrm{Mo}_{2} \mathrm{C}$ & $\mathrm{Mo}_{2} \mathrm{C}$ \\
\hline$\overline{\tau_{3}}$ & 61.4 & 12.4 & 7.6 & -14.4 \\
\hline (refs.) & $\mathrm{Fe}, \mathrm{C}$, & $\mathrm{Fe}, \mathrm{C}$, & $\mathrm{Fe}, \mathrm{C}$, & $\mathrm{Fe}, \mathrm{Fe}_{3} \mathrm{C}$ \\
\hline (refs.) & $\mathrm{Mo}_{2} \mathrm{C}$ & $\mathrm{Mo}_{2} \mathrm{C}$ & $\mathrm{Mo}_{2} \mathrm{C}$ & $\mathrm{Mo}_{2} \mathrm{C}$ \\
\hline
\end{tabular}

TABLE I: Formation energies (meV/atom) for binary and ternary phases for nanocatalysts of different sizes: $\mathrm{Fe}_{3} \mathrm{C}$, $\mathrm{Mo}_{2} \mathrm{C}, \mathrm{Fe}_{2} \mathrm{Mo}, \tau_{1}, \tau_{2}$ and $\tau_{3}$, calculated with respect to the reference species shown in the table.

of the particles have been calculated with the interpolation shown in Figure 2 of Ref. $\stackrel{22,23}{ }$. We investigate a very small particle with $N_{\text {atoms }} \sim 40$, which may able to support SWCNT growth $\frac{63}{}$. to explore size-induced stabilization trends. As seen from the zero temperature phase diagrams in Figure 1 and the energies in Table [1. $\mathrm{Mo}_{2} \mathrm{C}$ and $\mathrm{Fe}_{2} \mathrm{Mo}$ are stable for bulk materials as well as nanoparticles, while $\mathrm{Fe}_{3} \mathrm{C}$ and $\tau_{3}$ are stable only for small nanoparticles of radius $R \sim 0.41 \mathrm{~nm}\left(\mathrm{E}_{f}\left[\mathrm{Fe}_{3} \mathrm{C}\right] \leq 0\right.$ for $R<0.58 \mathrm{~nm}^{22,23}$ ). $\tau_{1}$ and $\tau_{2}$ are always unstable.

$\mathrm{Fe}_{4} \mathrm{Mo}$ particles. The most obvious advantage that a $\mathrm{Fe}_{4} \mathrm{Mo}$ particle has over a pure Fe particle is that the $\left[\mathrm{Fe}_{4 / 5} \mathrm{Mo}_{1 / 5}\right]_{1-x}-\mathrm{C}_{x}$ line does not intercept any carbide $\left(\mathrm{Fe}_{3} \mathrm{C}, \tau_{3}, \tau_{2}\right)$. This implies that, at least at low temperatures, there is a surplus of unbounded metal (probably even at high temperatures since the line is far from all of the competing stable phases). This is illustrated in Figure 2, which shows the fractional evolution of species as one progresses along the $\left[\mathrm{Fe}_{4 / 5} \mathrm{Mo}_{1 / 5}\right]_{1-x}-\mathrm{C}_{x}$ line in Figure 1.

Large $\mathrm{Fe}_{4} \mathrm{Mo}$ particles $(R \gtrsim 0.62 \mathrm{~nm})$. When a large $\mathrm{Fe}_{4}$ Mo particle $(R \gtrsim 0.62 \mathrm{~nm}$ in Figure 2 (a)) is exposed to carbon feedstock, the $\mathrm{Mo}_{2} \mathrm{C}$ phase nucleates by dissociating $\mathrm{Fe}_{2} \mathrm{Mo}$. This is seen for concentrations between $0<x_{c} \lesssim 0.09$. The vertical dashed line " 1 " in the figure indicates the boundary crossing of the $\left[\mathrm{Fe}_{4 / 5} \mathrm{Mo}_{1 / 5}\right]_{1-x^{-}}$ $\mathrm{C}_{x}$ pollution path with the $\mathrm{Fe} \leftrightarrow \mathrm{Mo}_{2} \mathrm{C}$ edge, as shown in Figure 1(c). Nucleation of $\mathrm{Mo}_{2} \mathrm{C}$ has two consequences: 

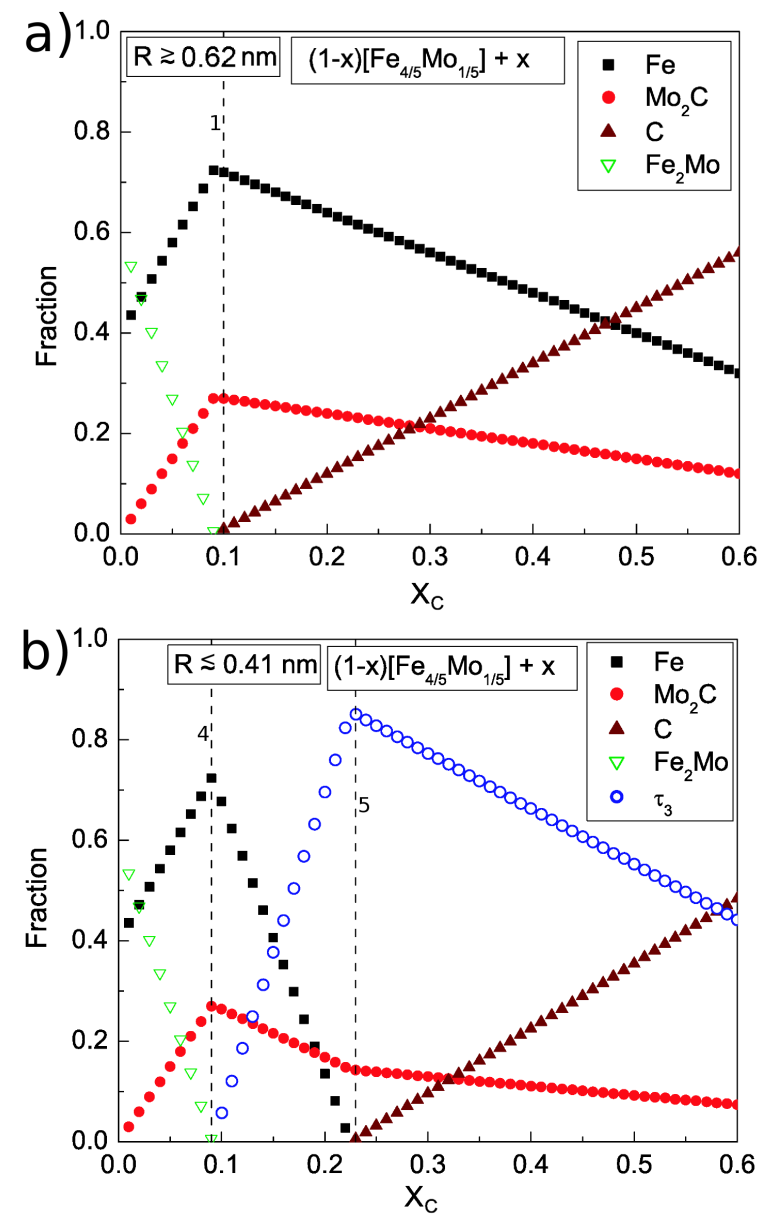

FIG. 2: (color online). Panel a). Fraction of species for catalyst composition $\left[\mathrm{Fe}_{4 / 5} \mathrm{Mo}_{1 / 5}\right]_{1-x}-\mathrm{C}_{x}$ and nanocatalyst of $R \gtrsim$ $0.62 \mathrm{~nm}$. The dashed vertical line, labeled as " 1 ", represents $\left[\mathrm{Fe}_{4 / 5} \mathrm{Mo}_{1 / 5}\right]_{1-x}-\mathrm{C}_{x}$ crossing the boundary phase $\mathrm{Fe} \leftrightarrow \mathrm{Mo}_{2} \mathrm{C}$, as shown in Figure 1(c). Panel b). Fraction of species for catalyst composition $\left[\mathrm{Fe}_{4 / 5} \mathrm{Mo}_{1 / 5}\right]_{1-x}-\mathrm{C}_{x}$ and nanocatalyst of $R \lesssim 0.41 \mathrm{~nm}$. The dashed vertical lines, labeled as "4" and "5", represent $\left[\mathrm{Fe}_{4 / 5} \mathrm{Mo}_{1 / 5}\right]_{1-x}-\mathrm{C}_{x}$ crossing the boundary phases $\mathrm{Fe} \leftrightarrow \mathrm{Mo}_{2} \mathrm{C}$ and $\tau_{3} \leftrightarrow \mathrm{Mo}_{2} \mathrm{C}$, as shown in Figure 1(d).

it consumes carbon atoms that are added to the particle by bonding them to molybdenum, and it releases free-Fe which is beneficial for the catalytic activity of the cluster (the Fe fraction increases with $\mathrm{C}$ concentration in the range $0<x_{c} \lesssim 0.09$ ). In addition, while forming $\mathrm{Mo}_{2} \mathrm{C}$, carbon does not produce SWCNTs. In fact, we need to saturate the particle in $\mathrm{C}$ and enter the region $\mathrm{Fe}-\mathrm{Mo}_{2} \mathrm{C}-$ SWCNT of the phase diagram in Figure 1(c) before free carbon is available. Hence, the fraction of $\mathrm{C}$ is non-zero only after $x_{c} \sim 0.09$ in Figure 2(a). For $x_{c} \lesssim 0.09$ the free $\mathrm{Fe}$ is expected to be on the particle surface since the fraction of free-Fe is larger than that of $\mathrm{Mo}_{2} \mathrm{C}$ and, as presented later, surface energy calculations show that free-Fe resides at the surface of the particle whereas the $\mathrm{Mo}\left(\mathrm{Mo}_{2} \mathrm{C}\right)$ parties found near particle core. To con- clude, steady state growth of SWCNTs is possible from large $\mathrm{Fe}_{4} \mathrm{Mo}$ particles since free, catalytically active $\mathrm{Fe}$ is present, even for $x_{c} \gtrsim 0.09$.

Small $\mathrm{Fe}_{4} \mathrm{Mo}$ particles $(R \lesssim 0.41 \mathrm{~nm})$. Similarly to the large $\mathrm{Fe}_{4} \mathrm{Mo}$ particle, initial exposure of the small $\mathrm{Fe}_{4} \mathrm{Mo}$ cluster $(R \lesssim 0.41 \mathrm{~nm})$ to carbon feedstock promotes $\mathrm{Mo}_{2} \mathrm{C}$ nucleation by dissociating $\mathrm{Fe}_{2} \mathrm{Mo}$ and releasing free Fe. However, for $x_{c} \gtrsim 0.09$ the scenario is different. In fact, while the fraction of free $\mathrm{Fe}$ increases between $0<x_{c} \lesssim 0.09$ (left of line "4" in Figure 2 (b)), it reduces to zero between $0.09 \lesssim x_{c} \lesssim 0.23$ (points " 4 " and "5" of Figure 1(d)). Concomitantly, the carbide $\tau_{3}$ nucleates by bonding carbon atoms that are added to the particle and hence eliminating the amount of free $\mathrm{Fe}$ that was released during the growth of $\mathrm{Mo}_{2} \mathrm{C}$. Similarly to $\mathrm{Fe}-\mathrm{C}$ particles ${ }^{22,23}$ with the carbide $\mathrm{Fe}_{3} \mathrm{C}$, the nucleation of $\tau_{3}$ is clearly detrimental for SWCNT growth. In fact, the lack of simultaneous presence of free-Fe and excess $\mathrm{C}$ causes the particle to be catalytically inactive. However, the different formation energies of $\tau_{3}$ and $\mathrm{Fe}_{3}$ lead to different size thresholds between the two regimes (growth/no-growth). In Refs $\stackrel{22,23}{2}$ we estimated that the minimum radius needed for a low-temperature Fe particle to be active is $R_{\text {min }}^{F e} \sim 0.58 \mathrm{~nm}$. For the $\mathrm{Fe}_{4} \mathrm{Mo}$ case, by interpolating the energies of $\tau_{3}$ reported in Table 【, by determining $P$ at which $E\left[\tau_{3}(P)\right]=0$, and by using the size/pressure approximation relation (1), we obtain $R_{\min }^{F e_{4} M o} \sim 0.52 \mathrm{~nm}$. The reduced size advantage $R_{\min }^{F e_{4} M o}<R_{\min }^{F e}$ agrees with experimental results that show that nanotubes, grown from Fe-rich Fe:Mo catalysts are thinner than those grown from pure Fe particles 20 . As pointed out before ${ }^{22,23}$, the presence of $R_{\min }^{\mathrm{Fe}_{4} \mathrm{Mo}}$ defines three possible thermodynamic scenarios: steady-state-, limited- and no-growth for $R>R_{\text {min }}^{F e_{4} M o}, R \sim R_{\min }^{F e_{4} M o}$ and $R<R_{\min }^{F e_{4} M o}$, respectively. It is worth mentioning that as long as the concentration of Mo in a Fe-rich Fe:Mo clusters is chosen to be slightly larger than that of $\tau_{3}$ we obtain $R_{\min }^{F e: M o}<R_{\min }^{F e}$.

FeMo test particles. To address the poor growth capability of Mo-rich Fe:Mo catalysts (low yield of SWCNTs at high temperature ${ }^{62}$ ) we repeated the above analysis with an equiconcentration FeMo particle. For simplicity, we choose to avoid dealing with the $\mathrm{Mo}_{5.1} \mathrm{FeO}_{7.9}$ phase reported at low temperature $e^{35,36}$ because, as our results show, its presence does not affect the pollution mechanism discussion.

Large FeMo particles $(R \gtrsim 0.62 \mathrm{~nm})$. Contrary to $\mathrm{Fe}_{4} \mathrm{Mo}$ particles, large FeMo clusters contain ample amounts of molybdenum capable of nucleating $\mathrm{Mo}_{2} \mathrm{C}$. Irrespective of whether $\mathrm{Mo}_{5.1} \mathrm{FeO}_{7.9}$ is included in the discussion, both free-Fe and an excess of $\mathrm{C}$ are present for $x_{c} \gtrsim 0.20$ (line " 3 " in Figure 3(a) and phase boundary " 3 " in Figure 1(c)). Hence, the growth SWCNTs is possible for $x_{c} \gtrsim 0.20$. However, since the fraction of $\mathrm{Fe}$ considerably smaller than that of $\mathrm{Mo}_{2} \mathrm{C}$, the activity of 

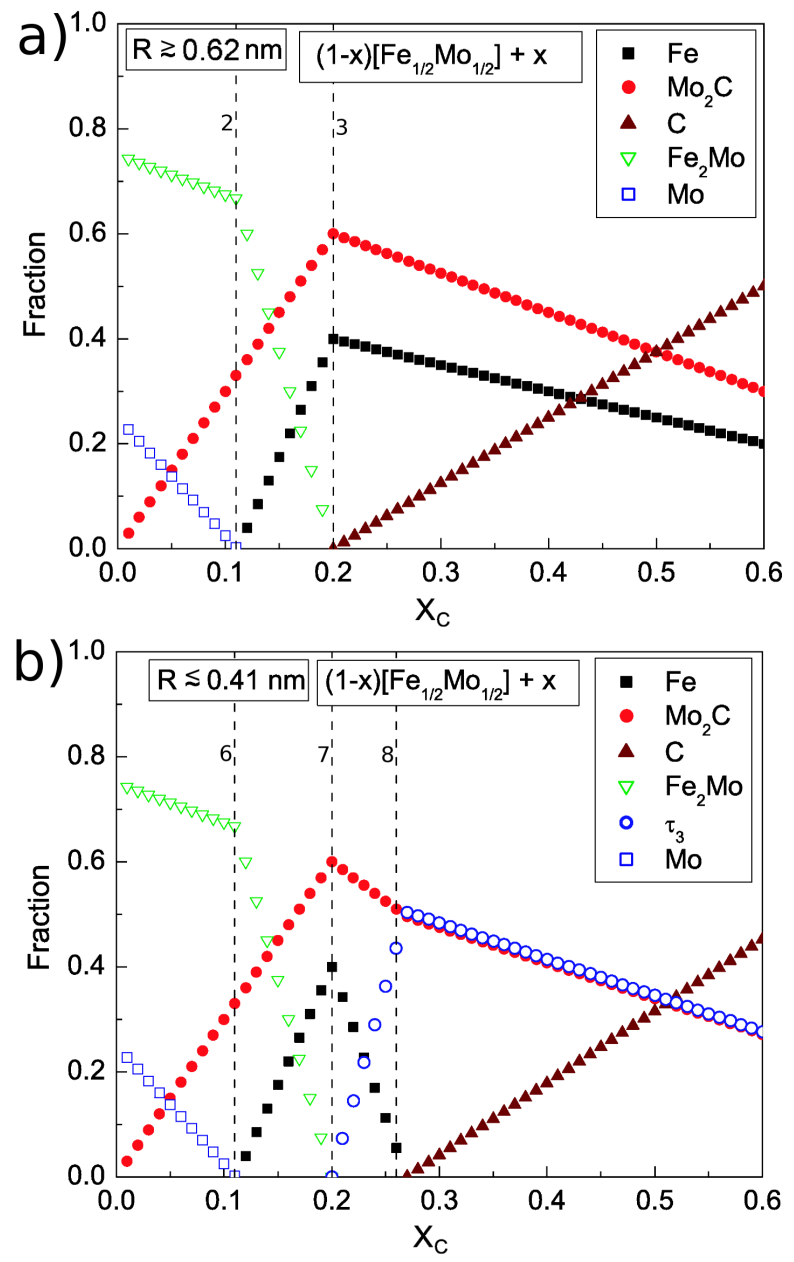

FIG. 3: (color online). Panel a). Fraction of species for catalyst composition $\left[\mathrm{Fe}_{1 / 2} \mathrm{Mo}_{1 / 2}\right]_{1-x}-\mathrm{C}_{x}$ and nanocatalyst of $\mathrm{R} \gtrsim 0.62 \mathrm{~nm}$. The dashed vertical lines, labeled as "2" and "3", represent $\left[\mathrm{Fe}_{1 / 2} \mathrm{Mo}_{1 / 2}\right]_{1-x}-\mathrm{C}_{x}$ crossing the boundary phases $\mathrm{Fe}_{2} \mathrm{Mo} \leftrightarrow \mathrm{Mo}_{2} \mathrm{C}$ and $\mathrm{Fe} \leftrightarrow \mathrm{Mo}_{2} \mathrm{C}$, as shown in Figure 1(c). Panel b). Fraction of species for catalyst composition $\left[\mathrm{Fe}_{1 / 2} \mathrm{Mo}_{1 / 2}\right]_{1-x}-\mathrm{C}_{x}$ and nanocatalyst of $\mathrm{R} \lesssim 0.41$ $\mathrm{nm}$. The dashed vertical lines, labeled as "6", "7" and " 8 ", represent $\left[\mathrm{Fe}_{1 / 2} \mathrm{Mo}_{1 / 2}\right]_{1-x}-\mathrm{C}_{x}$ crossing the boundary phases $\mathrm{Fe}_{2} \mathrm{Mo} \leftrightarrow \mathrm{Mo}_{2} \mathrm{C}, \mathrm{Fe} \leftrightarrow \mathrm{Mo}_{2} \mathrm{C}$, and $\tau_{3} \leftrightarrow \mathrm{Mo}_{2} \mathrm{C}$, as shown in Figure 1(d).

the whole FeMo particle is drastically smaller than that of the $\mathrm{Fe}_{4} \mathrm{Mo}$ catalyst. Thus, although it is possible to growth SWCNTs from large FeMo clusters, the expected yield is low and the synthesis temperature needs to be high (to overcome the reduced fraction of catalytically active free-Fe), as experimentally reported ${ }^{62}$. Thermodynamically, an excess of $\mathrm{C}$ and a amount of free-Fe for $x_{c} \gtrsim 0.20$ guarantees the existence of steady-state growth of SWCNTs (albeit slow and inefficient).

Small FeMo particles ( $R \lesssim 0.41 \mathrm{~nm}$ ). Small FeMo par- ticles are similar to small $\mathrm{Fe}_{4}$ Mo clusters. Nucleation of $\tau_{3}$ and the absence of free-Fe and excess $\mathrm{C}$ means that the particle is catalytically inactive. The minimum cluster radius, $R_{\min }^{F e M o}$ is the same as $R_{m i n}^{F e_{4} M o}$ because this quantity is determined by the stabilization of the same $\tau_{3}$ phase. Thus, there are three possible thermodynamic scenarios that are similar to the previous case, i.e., lowyield steady-state-, low-yield limited- and no-growth for $R>R_{\min }^{F e M o}, R \sim R_{\min }^{F e M o}$ and $R<R_{\min }^{F e M o}$, respectively. The analysis can be extended to different fractions of $\mathrm{Fe}$ and Mo and the results are summarized in Table $\amalg$.

\begin{tabular}{c|c|c}
\hline \hline catalyst & Fe-rich $\mathrm{Fe}_{1-x} \mathrm{Mo}_{x}$ & Mo-rich $\mathrm{Fe}_{1-x} \mathrm{Mo}_{x}$ \\
$x_{c}$ range & $x_{\tau_{3}}^{\star}<x<1 / 3$ & $x>1 / 3$ \\
(test) & $\mathrm{Fe}_{4} \mathrm{Mo}$ & FeMo \\
\hline$R>R_{m i n}^{F e M o}$ & steady-state growth & low-yield steady-state growth \\
$R \sim R_{m i n}^{F e M o}$ & limited growth & low-yield limited growth \\
$R<R_{\min }^{\mathrm{FeMo}}$ & no growth & no growth \\
\hline \hline
\end{tabular}

TABLE II: Scenarios of thermodynamically allowed SWCNT growth modes for different sizes and compositions of Fe:Mo catalysts. $x_{\tau_{3}}^{\star}$ is the concentration of Mo in $\tau_{3}$ removed of all C. $R_{\text {min }}^{F e M o}=0.52<R_{\text {min }}^{F e}=0.58 \mathrm{~nm}$ from Refs ${ }^{22,23}$.

Surface energies. The chemical species that are found on the surface of a Fe:Mo cluster with coexisting $\mathrm{Fe}$, and $\mathrm{Fe}_{2}$ Mo phases is the species that has the lowest surface energy per unit area, $\gamma$. This quantity can be obtained from the relation $\gamma=\left[E_{n}-n E_{B}\right] / 2 A$, where $E_{n}$ is the total energy of a $n$-layer slab, $E_{B}$ is the total energy of a single bulk layer, and $A$ is the surface of the unit cell (the factor two accounts for the creation of two surfaces $)^{64}$. For bcc Fe, we construct slabs with the lowest surface energy ( $\left.\begin{array}{lll}1 & 1 & 0\end{array}\right)$ termination 64 . Surface termination for the ordered $\mathrm{Fe}_{2}$ Mo phase has not been reported in experiments or in theoretical works. By using the package AFLOW, which performs high-throughput simultaneous optimization of planar density (high) and number of broken bonds (low) ${ }^{64,66}$, we find that the closed packed ( $\left.\begin{array}{lll}0 & 0 & 4\end{array}\right)$ plane of $\mathrm{Fe}_{2} \mathrm{Mo}$ has the lowest energy. We obtain $\gamma_{\mathrm{Fe}}^{(110)}=2.44 \mathrm{~J} / \mathrm{m}^{2}$ and $\gamma_{\mathrm{Fe}_{2} \mathrm{Mo}}^{(004)}=3.12 \mathrm{~J} / \mathrm{m}^{2}$. The relation $\gamma_{\mathrm{Fe}}<\gamma_{\mathrm{Fe}_{2} \mathrm{Mo}}$ indicates that Mo will not be at the cluster surface. Thus, in Fe-rich Fe:Mo nanocatalysts, Fe covers as much surface area as possible, and the aforementioned nucleation of $\mathrm{Mo}_{2} \mathrm{C}$ caused by $\mathrm{C}$ pollution is advantageous for the activity of the particle, by releasing free-Fe on the surface.

Conclusions. In this paper we discuss the role of Mo in the thermodynamic properties of Fe:Mo nanocatalysists by using the size-pressure approximation and $a b i n i$ tio modeling. We show that for both Fe-rich $(\sim 80 \% \mathrm{Fe}$ or more) and Mo-rich ( $\sim 50 \%$ Mo or more) Fe:Mo clusters, the presence of carbon causes nucleation of $\mathrm{Mo}_{2} \mathrm{C}$ which enhances the activity of the particle by releasing free-Fe. With respect to pure Fe-catalysts, the addition 
of Mo (up to small concentrations) decreases the size of the smallest catalyst needed for low-temperature CVD steady-state growth to $R_{\min }^{F e: M o} \sim 0.52 \mathrm{~nm}$.

Acknowledgement. We acknowledge helpful discussions with A. Kolmogorov, N. Li, T. Tan, E. Mora and F.
Cervantes-Sodi. The authors are grateful for computer time allocated at the Teragrid facilities. This research was supported by Honda Research Institute USA, Inc. SC is supported by ONR (N00014-07-1-0878) and NSF (DMR-0639822).
${ }^{1}$ C. Journet, W. K. Maser, P. Bernier, A. Loiseau, M. Lamy de la Chapelle, S. Lefrant, P. Deniard, R. Lee, and E. Fischer, Nature 388, 756 (1997).

2 A. Thess, R. Lee, P. Nikolaev, H. Dai, P. Petit, J. Robert, C. Xu, Y. H. Lee, S. G. Rinzler, D. T. Colbert, C. Xu, D. Tomanek, J. Fischer, and R. E. Smalley, Science 273, 483 (1996).

3 Y. Li, J. Liu, Y. Wang and Z. L. Wang, Chem. Mater. 13, 1008 (2001).

4 A. Moisala, A. G. Nasibulin and E. I. Kauppinen, J. Phys: Condens. Matter 15, S3011 (2003).

${ }^{5}$ K. Kakehi, S. Noda, S. Chiashi and S. Maruyama, Chem. Phys. Lett. 428, 381 (2006).

${ }^{6}$ H. Dai, A. Rinzler, P. Nikolaev, A. Thess, D. Colbert, and R. E. Smalley, Chem. Phys. Lett. 260, 471 (1996).

7 B. Kitiyanan, W. E. Alvarez, J. H. Harwell, and D. E. Resasco, Chem. Phys. Lett. 317, 497 (2000).

8 C. L. Cheung, A. Kurtz, H. Park, and C. M. Lieber, J. Phys. Chem. B 106, 2429 (2002).

9 H. W. Zhu, C. L. Xu, D. H. Wu, B. Q. Wei, R. Vajtai, and P. M. Ajayan, Science 296, 884 (2002).

10 A. R. Harutyunyan, B. K. Pradhan, U. J. Kim, G. Chen, and P. C. Eklund, Nano Lett. 2, 525 (2002).

11 A.-C. Dupuis, Prog. Mater. Sci. 50, 929 (2005).

${ }^{12}$ H. Kanzow and A. Ding, Phys. Rev. B 60, 11180 (1999).

13 M. Cantoro, S. Hofmann, S. Pisana, V. Scardaci, A. Parvez, C. Ducati, A. C. Ferrari, A. M. Blackburn, K. Y. Wang, and J. Robertson, Nano Lett. 6, 1107 (2006).

14 C. Klinke, J.-M. Bonard, and K. Kern, Phys. Rev. B 71, 035403 (2005).

15 M. Lin, J. P. Y. Tan, C. Boothroyd, K. P. Loh, E. S. Tok, and Y.-L. Foo, Nano Lett. 6, 449 (2006).

16 A. M. Cassel, A. Raymakers, J. Kong, and H. Dai, J. Phys. Chem. B 103, 6484 (1999).

${ }^{17}$ K. Hata, D. N. Futaba, K. Mizuno, T. Namai, M. Yumura, and S. Iijima, Science 306, 1362 (2004).

18 G. Zhang, D. Mann, L. Zhang, A. Javey, Y. Li, E. Yenilmez, Q. Wang, J. P. McVittie, Y. Nishi, J. Gibbons, and H. Dai, Proc. Natl. Acad. Sci. U.S.A. 102, 16141 (2005).

19 E. Mora, T. Tokune and A. R. Harutyunyan, Carbon 45, 971 (2007).

20 A. R. Harutyunyan, E. Mora, T. Tokune, K. Bolton, A. Rosén, A. Jiang, N. Awasthi, and S. Curtarolo, App. Phys. Lett. 90, 163120 (2007).

21 A. Jiang, N. Awasthi, A. N. Kolmogorov, W. Setyawan, A. Börjesson, K. Bolton, A. R. Harutyunyan, and S. Curtarolo, Phys. Rev. B 75, 205426 (2007).

22 A. R. Harutyunyan, N. Awasthi, A. Jiang, W. Setyawan, E. Mora, T. Tokune, K. Bolton, and S. Curtarolo, Phys. Rev. Lett. 100, 195502 (2008).

23 S. Curtarolo, N. Awasthi, W. Setyawan, N. Li, A. Jiang,
T. Y. Tan, E. Mora, K. Bolton, A. R. Harutyunyan, Thermodynamics of carbon in iron nanoparticles at low temperature: reduced solubility and size-induced nucleation of cementite, Proc. Computer Simulation Studies in Condensed Matter Physics XXI, Eds. D. P. Landau, S. P. Lewis and H.-B. Schüttler, (Springer, Berline, Heidelberg, 2008).

24 S. Maruyama, R. Kojima, Y. Miyauchi, S. Chiashi, and M. Kohno, Chem. Phys. Lett. 360, 229 (2002).

25 N. Pernicone, Cat. Today 11, 85 (1991).

${ }^{26}$ W. L. Wang, X. D. Bai, Z. Xu, S. Liu, and E. G. Wang, Chem. Phys. Lett. 419, 81 (2006).

27 N. Shah, D. Panjala, and G. P. Huffman, Energy \& Fuels 15, 1528 (2001).

28 N. Shah, S. Pattanaik, F.E. Huggins, D. Panjala, and G. P. Huffman, Fuel Process. Technol. 83, 163 (2003).

29 E. Flahaut, A. Govindaraj, A. Peigney, Ch. Laurent, A. Rousset and C. N. R. Rao, Chem. Phys. Lett. 300, 236 (1999).

30 H. Ago, N. Uehara, N. Yoshihara, M. Tsuji, M. Yumura, N. Tomonaga, and T. Setoguchi, Carbon 44, 2912 (2006).

31 S. Tang, Z. Zhong, Z. Xiong, L. Sun, L. Liu, J. Lin, Z. X. Shen, and K. L. Tan, Chem. Phys. Lett. 350, 19 (2001).

32 W. E. Alvarez, B. Kitiyanan, A. Borgna and D. E. Resasco, Carbon 39, 547 (2001).

33 J. E. Herrera, L. Balzano, A. Borgna, W. E. Alvarez, and D. E. Resasco, J. Catal. 204, 129 (2001).

34 E. Lamouroux, P. Serp, Y. Kihn, and P. Kalck, Appl. Catalysis A 323, 162 (2007).

35 T. B. Massalski (Ed.), Binary Alloy Phase Diagrams, ASM International, Metals Park, OH (1992).

36 P. Villars, K. Cenzual, J. L. C. Daams, F. Hulliger, T. B. Massalski, H. Okamoto, K. Osaki, A. Prince, and S. Iwata, Binaries Edition, ASM International, Metal Park, OH (2003).

37 Z. Niu and Y. Fang, J. Cryst. Growth, 297, 228 (2006).

38 K. Omuro, H. Miura, and H. Ogawa, Mat. Sc. Eng. A 181-182, 1281 (1994).

39 A. Oya and S. Otani, Carbon 17, 131 (1979).

40 J. E. Herrera and D. E. Resasco, J. Catal. 221, 354 (2004).

41 A. Gorbunov, O. Jost, W. Pompe, and A. Graff, Carbon 40, 113 (2002).

${ }^{42}$ H. S. Kim, Y. Kobayashi, and K. Nagai, J. Mat. Res. 21, 1399 (2006).

43 S. Bairs, Journal of Colloid and Interface Science 302, 312 (2006).

44 G. Kresse and J. Hafner, Phys. Rev. B 47, 558 (1993).

45 P. E. Blochl, Phys. Rev. B 50, 17953 (1994).

46 J. P. Perdew, K. Burke, and M. Ernzerhof, Phy. Rev. Lett. 77, 3865 (1996).

47 G. P. Francis and M. C. Payne, J. Phys.: Condens. Matter 2, 4395 (1990). 
${ }^{48}$ K. Bolton, F. Ding, A. Borjesson, W. Zhu, H. Duan, A. Rosen, A. R. Harutyunyan, and S. Curtarolo, Computational studies of catalytic particles for carbon nanotube growth, Journal of Theoretical and Computational Nanoscience, in press (2008).

49 V. G. Rivlin, Int. Metals Rev. 30, 109 (1985).

${ }^{50}$ P. Ettmeyer and R. Suchentrunk, Monatsh. Chem. 101, 1098 (1970).

${ }^{51}$ K. Kuo, Acta. Metall. 1, 301 (1953).

${ }^{52}$ W. B. Pearson, A Handbook of lattice spacings and structures of metals and alloys, Vol. 1, Vol. 2, Oxford, Pergamon (1958, 1967).

53 D. J. Dyson and K. W. Andrews, J. Iron Steel Inst. 202, 325 (1964).

${ }^{54}$ K. Kuo, J. Iron Steel Inst. 173, 363 (1953).

55 H. Krainer, Arch. Eisenhuttenwes. 21, 39 (1950).

56 J. Janovec, M. Svoboda, A. Vyrostkova, and A. Kroupa, Mat. Sc. Eng. A 402, 288 (2005).

57 S. Curtarolo, D. Morgan, K. Persson, J. Rodgers, and G. Ceder, Phys. Rev. Lett. 91, 135503 (2003).

58 S. Curtarolo, D. Morgan, and G. Ceder, Calphad 29, 163 211 (2005).
59 A. N. Kolmogorov and S. Curtarolo, Phys. Rev. B 73, 180501(R) (2006).

60 A. N. Kolmogorov and S. Curtarolo, Phys. Rev. B 74, 224507 (2006).

61 Qhull software, available at the homepage www.qhull.org

62 Our studies show that increasing the Mo-Fe ratio results in poor yield of nanotubes (according to TGA measurements) and poor quality (according to the Raman Ig/Id ratio measurements). A. R. Harutyunyan, private comunications (2007).

${ }^{63}$ F. Ding, A. Rosén, and K. Bolton, J. Chem. Phys., 121, 2775 (2004).

${ }^{64}$ P. Bloński and A. Kiejna, Surf. Sc. 601, 123 (2007).

65 Our calculations for bulk bc- Fe show that Mo prefers a substitutional position over interstitial. The calculation was done for a bcc Fe unitcell $(3 \times 3 \times 3)$ with 27 atoms in which one Fe was substituted by Mo. Formation energies are calculated with the usual framework ${ }^{57,60}$.

66 S. Curtarolo, D. D. Morgan, and A. van der Ven, Aflow: a package for high-throughput calculations of materials properties, unpublished. 